\title{
DELAMINATION DETECTION USING ELECTRICAL RESISTANCE CHANGE METHOD AND ITS RELIABILITY
}

\author{
Nikola SCHMIDOVÁ ${ }^{1}$, Milan RŮŽIČKA ${ }^{1}$, Karel DOUBRAVA ${ }^{1}$ and Milan DVOŘÁK ${ }^{1}$ \\ 1 Department of Mechanics, Biomechanics and Mechatronics, Faculty of Mechanical Engineering, \\ Czech Technical University in Prague, Technická 4, 160 00, Praha, Czech Republic, E-mail: \\ Nikola.Schmidova@fs.cvut.cz
}

\section{Introduction}

The reliability of delamination detection on Carbon Fiber Reinforced Polymer (CFRP) composites with thermoplastic matrices using Electrical Resistance Change Method (ERCM) was investigated. The ERCM is based on measuring electrical resistance change and it is used mainly for the CFRP composites or glass-fiber reinforced composites doped with conductive particles. The results measured using the ERCM are influenced by the contact configuration, nominal resistivity of the material, environmental conditions such as temperature and mechanical loading of the material. The method can serve for different purposes of Structural Health Monitoring (SHM). Several configurations of the electrical contacts have been proposed for various measurement/detection scenarios, such as an impact detection [1,2], delamination detection $[3,4]$ or detection of transverse cracks [5]. The ERCM method is most often studied in connection with the delamination detection. One of the typical application for which is the ERCM intended is the delamination detection after impact in an aircraft fuselage and wings area. For this particular application the configuration of the contacts has to be situated on one face, which is not the most effective contact configuration for the delamination detection. It was shown, that the contact configuration for through-thickness or oblique measurement is more convenient [1]. Although number of papers are dedicated to impact localization on a CFRP plate with electrical contacts on one face [2, 4], no such attention is paid to measurements with contacts located on both faces. This configuration could be successfully used for many other typical structural elements which can be also typically damaged by delamination such as curved components, skin stringers in an aircraft structure or components with ply drop. For these types of components there is also a need for reliable SHM and there is no problem with placing contacts on both sides of the material. The presented research is therefore focused on components, where contacts can be placed on both sides.

\section{Material and Specimen Preparation}

Delamination detection using ERCM was studied on the specimens made of carbon fabric with Polyphenylene Sulphide resin (CF-PPS), material sheet AIMS05-09-002. Six specimens with the dimensions $5 \times 15 \times 54 \mathrm{~mm}$ were cut from one sheet of the material. Surface of the specimens was slightly sanded at first with sandpaper P120 and P600 and then degreased. Electrical contacts were prepared using a CHO-BOND ${ }^{\circledR}$ 584-29 conductive epoxy and copper strips. To initialize the delamination, specimens were partly cut in the half of the thickness. Afterwards the delamination growth was forced mechanically. Experimental data measured during the delamination growth were compared to those obtained during the delamination growth on the specimens made of carbon fabric prepreg with thermoset polymer matrix (CF-epoxy). The configuration of the electrical contacts on the specimens are given in Fig. 1. The specimens made of CF-epoxy were loaded simultaneously by mode I and mode II loading (Mixed-Mode Bending - MMB specimens). Experimental results were already published in [6]. The MMB specimens were extracted from CFRP composite made of 16 layers. Dimensions of the specimens were $3.3 \times 25 \times 185 \mathrm{~mm}$. A $25 \mathrm{~mm}$ long non-adhesive plastic foil sheet was inserted to the plate edge during manufacturing to the neutral axis to initiate the delamination.

\section{Measurement Procedure}

The measurement was performed using the HP E3631A current source and two Agilent 34461A multimeters. The change in electrical resistance was determined using the series comparison measurement method. The resolution of the measurement was $\pm 0.01 \mathrm{~m} \Omega$ and the accuracy of 
the measurement was $\pm 0.03 \mathrm{~m} \Omega$. Value of the measurement accuracy is the limit for the reliable measurement. The reliable detection of the delamination growth is limited by the minimal detectable resistivity change.

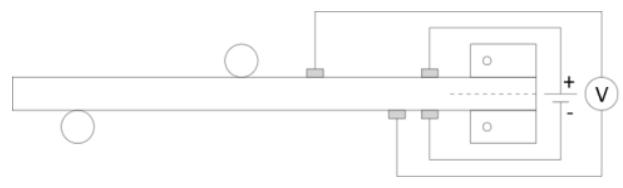

(a) MMB CF-epoxy

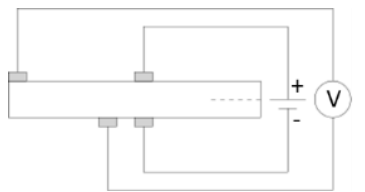

(b) DCB CF-PPS

Fig. 1. Measurement configuration of the electrical resistance measurement - configuration of duty current injection and voltage change measurement on the CF-

epoxy specimen (a), CF-PPS specimen (b).

\section{Experimental Results}

The electrical resistance of each CF-PPS specimen was measured before an initialization of the delamination and after each delamination growth (increment). Delamination growth was recorded using a Nikon camera. Measured values of electrical resistivities were used in the numerical simulation of the delamination growth. Results of the experimental and numerical investigations are given in Fig. 2 as a relative change of measured electrical resistance.
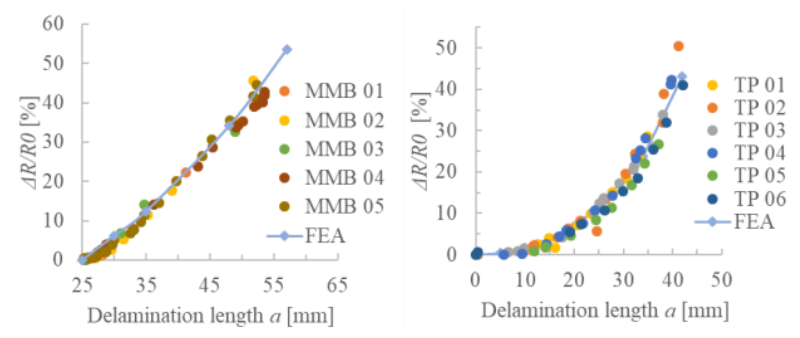

Fig. 2. Comparison of experimental results and numerical simulation results of delamination growth on the CF-epoxy specimen (left) and CF-PPS specimens (right).

The $R_{0}$ in the equation corresponds to the initial electrical resistance. For the MMB CF-epoxy specimen the initial resistance was measured before delamination growth, when the delamination was only $25 \mathrm{~mm}$. For the DCB CF-PPS specimen the initial resistivity was determined on the specimen without delamination.

\section{Conclusions}

The experimental investigation and the numerical simulation of the delamination growth on the specimens made of CF-PPS and CF-epoxy resin were performed. Comparison of the numerical and the experimental results has shown good agreement. The influence of the temperature change, values of the nominal resistivity and distance of the electrical contacts was also studied using the finite element analysis.

\section{Acknowledgements}

The authors would like to thank the TACR for supporting this research with project no. TE02000032 and Grant Agency of the CTU in Prague for supporting this research with grant No. SGS18/175/OHK2/3T/12.

\section{References}

[1] Wang, S., D.D.L. Chung and J.H. Chung. 2005. "Impact damage of carbon fiber polymer-matrix composites, studied by electrical resistance measurement," Composites, 36:1707-1715.

[2] Baltopoulos, A, N. Polydoride, L. Pambaguian, A. Vavouliotis amd V. Kostopoulos. 2012. "Damage identification in carbon fiber reinforced polymer plates using electrical resistance tomography mapping," Journal of Composite Materials, 47:3285-3301

[3] Todoroki, A. 2001. "The effect of number of electrodes and diagnostic tool for the delamination of CFRP laminates by changes in electrical resistance," Composite Science and Technology, 61:1871-1880.

[4] Atsushi, I., and A. Todoroki. 2005. "Statistical evaluation of modified electrical resistance change method for delamination monitoring of CFRP plate," Structural Health Monitoring , 4(2):119-136.

[5] Selvakumaran, L., Q. Long, S. Prudhomme and G. Lubineau. 2015. " On the detectability of transverse cracks in laminated composites using electrical potential change measurement," Composite Structures, 121:237-246.

[6] Schmidova, N, M. Dvorak, M. Kadlec and M. Ruzicka. 2018. "Monitoring of delamination growth on the MMB specimens using FBG sensors and electrical resistance measurement," Proceedings of 56th conference on experimental stress analysis EAN 2018, Praha. 